\title{
Sobre os limites do saber
}

\author{
Elisabete Thamer
}

\begin{abstract}
Resumo
O presente artigo articula alguns pontos extraídos da experiência de passe da autora, que pretende que uma modificação da relação do sujeito com o saber é necessária para o término de uma análise. $\mathrm{O}$ atravessamento da fantasia constitui uma etapa fundamental e imprescindível desse processo, mas não é suficiente para obter o esgotamento da paixão do deciframento que está em jogo na análise.
\end{abstract}

\section{Palavras-chave:}

Fim de análise; Saber inconsciente; Passe; Atravessamento da fantasia.

\section{On the limits of knowledge}

\begin{abstract}
This article presents a few concerns resulting from the author's experience of the pass and proposes that a modification of the subject's relationship with knowledge is necessary to complete an analysis. The traversing of fantasy is a fundamental and essential step in this process; however, it is not sufficient to decrease the passion for interpretation that is at stake in an analysis.
\end{abstract}

\section{Keywords:}

Completion of analysis; Unconscious knowledge; Pass; Traversing of fantasy.

\section{Sobre los límites del saber}

\begin{abstract}
Resumen
El presente artículo articula algunos puntos extraídos de la experiencia de pase de la autora, que pretende que una modificación de la relación del sujeto con el saber es necesaria para el fin de un análisis. El cruce de la fantasía constituye una etapa fundamental e imprescindible de ese proceso, pero no es suficiente para obtener el agotamiento de la pasión del desciframiento que está en juego en el análisis.
\end{abstract}

\section{Palabras clave:}

Fin de análisis; Saber inconsciente; Pase; Cruce de la fantasía. 


\section{Sur les limites de la connaissance}

\section{Résumé}

Cet article articule quelques points extraits de l'expérience de la passe de l'auteur, qui affirme qu'une modification de la relation du sujet avec le savoir est nécessaire pour la fin d'une analyse. La traversée du fantasme constitue une étape fondamentale et indispensable de ce processus, mais il ne suffit pas d'arriver l'épuisement de la passion du déchiffrage pour que cela ait lieu, ce qui est en jeu pour l'analyse.

\section{Mots-clés:}

Fin de l'analyse; Savoir inconscient; Passe; Traversée du fantasme.

Antes de abordar a questão da função do AE, Analista da Escola, gostaria de lhes dizer algo sobre o que extraí de essencial de minha experiência de análise, pois, em meu entender, há certa correlação entre os dois. Ao afirmar "a psicanálise didática”, Lacan (1966/1998, p. 76) postula que, no fundo, toda análise é formadora, pois nos ensina algo. Isso vai além do tratamento.

Muitas são as esperanças de quem começa uma análise. Porém, quanto mais ela avança, mais fica evidente, para o sujeito, que uma análise não pode tudo. Ela poderá livrá-lo de muitos de seus sintomas, mas não poderá erradicar todos eles; ela lhe permitirá obter certo saber sobre si mesmo, mas não um saber “todo”. É por isso que considero que uma das questões cruciais da psicanálise é, justamente, o que fará o analisante com esse hiato existente entre o que o dispositivo analítico lhe proporcionou e o que lhe foi impossível obter.

Visto sob esse ângulo, a perspectiva pode parecer desalentadora ou aleatória, mas não o é. Ela não é desalentadora, e Lacan insistiu sobre os afetos positivos que marcam uma análise conduzida até seu termo, evocando primeiramente o "entusiasmo" na Nota italiana (Lacan, 1973/2003a, p. 313) e, mais tarde, a "satisfação" no Prefácio à edição inglesa do Seminário 11 (Lacan, 1976/2003, p. 568). Esses afetos não são tampouco aleatórios, mas signos resultantes de uma lógica singular, que traça os parâmetros de uma conclusão. Como obter, então, um final de análise cuja satisfação seja a marca de fabricação, se muitas das expectativas de entrada são frustradas?

Os limites da psicanálise são vários, alguns deles oriundos de seu único instrumento, a fala. Esta não somente é imprópria para apreender o real do qual provém grande parte das aflições do sujeito, mas também carreia, em seu exercício, boa parte de gozo.

Existem ainda outros impasses intrínsecos ao dispositivo analítico e que se juntam aos da fala. Dois de seus conceitos fundamentais condensam, a meu ver, um impasse crucial para o desfecho de uma análise, a saber: os conceitos de inconsciente e de transferência. Em O ato psicanalítico, Lacan (1969/2003, p. 372) redefine o inconsciente dizendo que o fato de "que haja inconsciente significa que há um saber 
sem sujeito". Sobre a transferência, ele nos dá esta fórmula simples em 1973: "é amor que se dirige ao saber" (Lacan, 1973/2003b, p. 555). Esse simples cotejamento nos mostra que a hipótese transferencial, que espera obter um saber e sem o qual não há análise, está fadada à frustração, em razão da própria natureza do inconsciente. Não somente essa definição põe o saber inconsciente fora do alcance do sujeito, contradizendo a noção prévia de "sujeito do inconsciente", mas Lacan insiste ainda sobre outro ponto: o inconsciente "é um saber que não pensa, não calcula e não julga" e, ademais, ele é der Arbeiter, um trabalhador ideal, que nunca faz greve (Lacan, 1974/2003, p. 517). Ou seja, não há final de análise cuja solução provenha do inconsciente. Se o término, por definição, não provém do inconsciente, de onde pode vir ele, senão do próprio sujeito? Ou, mais precisamente, do modo como ele se mantém ligado, ou não, a seu próprio inconsciente? Essa é a razão pela qual penso que a chave de uma análise finita se encontra em uma virada radical na posição do sujeito quanto ao saber, saber que é o denominador comum entre as duas definições que destaquei e que são, em aparência, contraditórias.

Agora devemos nos colocar a seguinte questão: o "saber” que está em jogo nas duas definições é o mesmo? Segundo Lacan, foi necessária a criação da psicanálise para que a questão do "saber" fosse renovada, pois ela demonstra, justamente, que há saber que não se sabe. Assim, fica evidente que o "saber”, em psicanálise, não é unívoco, pois temos, de um lado, o saber articulado, enunciável em termos de linguagem: "para o ser falante", diz Lacan (1972-1973/2008, p. 188) no Seminário 20, “o saber é o que se articula". Do outro lado, temos o saber inconsciente, efeito de lalíngua e que ultrapassa o que o sujeito pode enunciar em termos de linguagem. O saber articulado, que vai de um significante a outro, engendra necessariamente uma falta-a-saber, mantendo o sujeito em uma busca constante de complemento de saber. Creio poder afirmar que o saber esperado pelo analisante, em todo caso, antes que o momento de passe venha revirar tudo isso, é a espera de um saber enunciável e causal, no sentido clássico do termo, ou seja, a ideia de que, "conhecendo" a causa, seus sintomas desapareceriam. A análise mostra que esse é o caso de alguns sintomas, mas não de todos.

Os efeitos do deciframento, ligados aos benefícios do endereçamento da fala sob transferência, asseguram efeitos terapêuticos não negligenciáveis. Ainda bem! Muitos analisantes, aliás, se contentam com esses ganhos, e isso não é necessariamente um problema, se eles não têm a pretensão de um dia serem psicanalistas. Os efeitos terapêuticos são, porém, uma faca de dois gumes com respeito à conclusão da análise, pois podem vir a sustentar, do lado do analisante, a esperança de um dia obter um efeito terapêutico maior, definitivo e radical, que o livre do destino que lhe impõe seu inconsciente. Como disse Lacan no mesmo Seminário 20, por causa do "que vem ao dito como consequência”, uma análise não chega sempre a fazer ex-sistir um dizer, do qual depende justamente seu término (Lacan, 1972-1973/2008, p. 34). 


\section{Finais}

Sabemos que Lacan não cessou de elaborar a questão do final de análise, tendo avançado progressivamente critérios para discerni-lo, como a queda das identificações, passando pelo atravessamento da fantasia, até a identificação com o sintoma, que é solidária de suas elaborações sobre o inconsciente real. O que me parece importante salientar é que nenhuma de suas elaborações progressivas invalida as precedentes, mas as completa. Observamos que as comunidades analíticas às vezes elegem uma ou outra dessas elaborações, transformando-a em uma espécie de orthe doxa, formatando, assim, suas expectativas com relação ao passe. De vez em quando, um conceito se torna agalmático, fazendo barreira a que nos deixemos instruir pelo singular de cada análise.

\section{Atravessamento da fantasia}

É por essa razão que gostaria de abordar um ponto que talvez, hoje em dia, seja considerado "cafona", comparado às últimas elaborações de Lacan, ou seja, o atravessamento da fantasia. Poderiam me perguntar: por que abordar essa questão tão batida? Justamente porque nenhuma análise pautada pelas elaborações de Lacan sobre o fim de análise, incluindo a identificação com o sintoma, pode prescindir dessa passagem, em que, justamente, a segurança que o sujeito extraía de sua fantasia é soçobrada. Por que o dito "atravessamento da fantasia" é imprescindível para se concluir uma análise? Porque é ele que desmantela o arcabouço dos sintomas-verdade que, ao longo de uma vida, ligaram o sujeito a um grande Outro hipotético. Pouco tempo após a divulgação da Proposição de 9 de outubro de 1967 sobre o psicanalista da escola (1967/2003), Lacan (1967/1968, p. 148) havia afirmado que "o valor de uma psicanálise é o de operar sobre o fantasma". Ora, falar em "valor da psicanálise” é uma apreciação, um julgamento que porta Lacan sobre o alcance da psicanálise. E, sem dúvida, não há análise que se possa considerar como terminada sem que o gozo ligado à fantasia tenha sido tocado, pois é somente ao perder toda significação que a fantasia "toca no real" (Lacan, 1972/2003, p. 489). A queda dessa "ficção" poderá, eventualmente, permitir que o sujeito perceba, enfim, a dimensão real de seu inconsciente. Voltarei a esse ponto.

Observem que se trata, aqui, de algo que a análise pode propiciar, um campo no qual ela prova sua eficácia. Apesar da insuficiência do deciframento e da fuga do sentido, existe um sentido que a análise escreve, e ela o escreve porque ele insiste, $\mathrm{e}$ trata-se justamente do sentido da fantasia. Ele é o único sentido que insiste ao longo da análise, em alguns sintomas, nas queixas, no léxico do analisante, em alguns significantes e cenários condensadores de gozo. A fantasia "é algo que resiste, que não é permeável a todos os sentidos” (Lacan, 1970-1971/2009, p. 27). Atravessar a fantasia não é, evidentemente, se livrar dela de uma vez por todas, mas "realizar" sua dimensão ficcional, forjada e contingente, cujo autor é o próprio sujeito, que, entretanto, imputava até então esse enredo a um Outro que não existe. 
Foi assim que, no sonho do qual apreendi a estrutura de minha fantasia, uma palavra, neológica, introduzia o conteúdo onírico, cujo cenário, obviamente, me era extremamente familiar; e uma expressão marcava a conclusão, com a seguinte exclamação: "Não é isso!".

A palavra que o introduzia era um misto de "bete", que além de ser o modo como me chamam aqui no Brasil as pessoas próximas, evoca também o adjetivo "bête", que, em francês, quer dizer "bobo", "besta", com o verbo grego semainein, que quer dizer "significar", e que era, naquele momento, um termo importante para a tese em filosofia que eu estava escrevendo. Concluí, então, que esse neologismo sonhado queria dizer simplesmente: "uma significação boba". O cenário da fantasia, até então grave, se desvelou a partir daquele momento como uma espécie de equívoco e do qual a expressão final - "Não é isso!" - denotava a separação. Desse sonho, não havia nada mais para extrair; ele não carecia de interpretações ou de associações, são as mudanças na vida que podem testemunhar que algo se desfez aí.

"Realizar" que a fantasia é uma ficção da qual somos o autor implica um efeito de separação e, necessariamente, uma mudança de afeto, pois, experimentando a inconsistência do Outro, modificam-se definitivamente as relações do sujeito com os outros, mas também com o saber. Esse desmantelamento modifica necessariamente os investimentos libidinais, pois as restrições imaginárias e simbólicas são abrandadas. O gozo ligado à fantasia perde sua força, deixando subsistir apenas a pulsão, talvez um estilo, mas também alguns gostos que não são estranhos ao que um dia foram os sulcos pelos quais o sujeito tentou acoplar seu desejo a um Outro que não existe. Enquanto o sujeito tomar a ficção da fantasia como real, não haverá absolutamente o atravessamento que lhe permitirá concluir a análise.

\section{Rumo ao inconsciente real, ou o luto do saber articulado}

A travessia da fantasia é, portanto, uma etapa fundamental do final de análise, mas é ela suficiente? Ela é o sinal de que a relação do sujeito com o saber foi modificada? Parece-me que se trata de uma passagem necessária, mas não suficiente, para a mudança da relação do sujeito com o saber, mudança que me parece essencial para o exercício da função analítica.

Ela não é suficiente, porque o saber ligado à fantasia é um saber ficcional, mas enunciável; pode-se, aliás, testemunhar sobre essa "verdade mentirosa". O problema é que, apesar disso, o inconsciente não cessará de cifrar o gozo, e nem todo gozo é arrimado na fantasia. $\mathrm{O}$ atravessamento da fantasia é suficiente para assegurar que o sujeito se desliga do gozo que o atrela ao deciframento, isto é, a seu inconsciente? Alguém pode continuar amoroso de seu inconsciente e de suas formações apesar do atravessamento da fantasia?

Penso que a análise pode levar o analisante ainda um pouco mais longe, liberando-o de sua paixão do deciframento, e isso não poderá de modo algum vir de seu 
próprio inconsciente. Nenhuma interpretação poderá modificar o inconsciente, mas, eventualmente, o gozo de sentido (joui-sens) que gruda o analisante a seu inconsciente. Não existem sonhos ou lapsos providenciais que virão determinar o fim, oferendo ao sujeito um material excepcional, um sonho "grand cru" que lhe permitirá concluir. Isso é apenas anseio de analisante, talvez de alguns analistas. A análise não modifica o inconsciente, mas modifica certamente o sujeito, pois pode modificar o modo como ele lê as formações de seu inconsciente, chegando mesmo a desconectá-lo dele. Se os testemunhos de passe são ricos em exemplos de sonhos ou lapsos inesquecíveis, eles o são não porque estes eram excepcionais, mas porque o sujeito não os leu mais como antes. A meu ver, é isso que marca a virada, e não o inverso.

Diante desta famosa citação de Lacan (1976/2003, p. 567): “quando (...) o espaço de um lapso - já não tem nenhum impacto de sentido (ou de interpretação), só então temos certeza de estar no inconsciente. O que se sabe, consigo", devemos nos perguntar: para quem um lapso não teria mais impacto de sentido senão para o próprio sujeito? É ele que não imputa mais sentido a seu lapso, e não o contrário. É o sujeito que, não buscando mais se representar junto ao significante de seu lapso, não o lê mais, podendo, destarte, relegá-lo ao real fora de sentido. Eu situaria aí a finalização do luto de um furo no saber. O sujeito sabe, então, que sabe o suficiente para concluir.

Isso acarreta uma reorganização dos gozos, pois permite ao sujeito concluir que existe um gozo opaco que a análise não poderá eliminar. Apesar da opacidade de uma parte do gozo refratário ao deciframento, o analisante sabe que esse inconsciente, que estará sempre fora de seu alcance, é bem "seu” inconsciente, porque esse saber inconsciente que o excede afeta seu corpo, corpo que não é o sujeito. Ele saberá se virar com isso.

A satisfação que marca o final é um índice de que o sujeito foi modificado por sua análise, no modo como suporta sua incurável divisão. $\mathrm{O}$ afeto de satisfação, pelo fato de atingir o corpo, indica algo lá onde o significante fracassa, atestando, desse modo, que a relação do sujeito com certo real foi tocada; pelo menos esse real que, aparecendo desde então como impossível, desvencilha o sujeito de suas impotências. Esse ponto vai, com certeza, bem mais além do que se pode testemunhar como saber articulado, como essa "verdade mentirosa" que, no fim das contas, não é nada mais nada menos do que uma "significação boba".

"Pela primeira vez na história", diz Lacan (1973-1974, inédito) em Os não-tolos erram, "lhes é possível, a vocês, errar, quer dizer, recusarem-se a amar seu inconsciente, pois que afinal vocês sabem o que ele é: um saber. Um saber que chateia (un savoir emmerdant)".

\section{A função do $A E$}

Inventando o dispositivo do passe, Lacan forjou uma maneira de interrogar continuamente o saber do psicanalista. Ele instalou um procedimento que tira o sossego dos que se pretendem analistas, incitando-nos constantemente a interrogar essa 
"sombra espessa" que paira sobre a passagem de analisante a analista. Pois a tendência, mesmo entre os "melhores" analistas, é de se repousar sobre saberes já adquiridos, correndo o risco de fazer esmorecer o desejo de saber que deve animar nossa prática. O mínimo que podemos dizer é que o passe provoca um desassossego no conjunto da comunidade, um desassossego cujo objetivo é nos impulsionar ao trabalho, impedindo que a rotina se cristalize em certezas que nos afastem da singularidade de cada caso, que traz sempre um saber novo. No âmbito da escola, a função do AE é tentar manter no centro esse furo no saber, que, às vezes, perturba. Para esse movimento, contribuem todos aqueles que participam do dispositivo: AME (Analista Membro da Escola), passadores, passantes, nomeados ou não. Trata-se de uma aposta coletiva, que não nos deixa esquecer que "há um real em jogo na própria formação do psicanalista”, e que esse real, como nos alertou Lacan (1967/2003, 249), "provoca seu próprio desconhecimento, ou até produz sua negação sistemática”. A existência de um furo no saber não significa que devamos nos enveredar por uma apologia do "não saber", contra a qual Lacan, aliás, se indignou. Trata-se, antes, do que temos a saber, a tentar saber.

O pior que pode ocorrer a uma escola é que ela pare de pensar sua função de escola, cujo telos é a formação de analistas. A responsabilidade é imensa, e não se trata somente de uma formação de tipo acadêmico. Uma escola de psicanálise também não pode funcionar somente por cooptação, relações de amizade ou meritocracia, senão o que nos diferenciaria da universidade ou de outros grupos? O cartel e o passe são as duas invenções de Lacan que nos ajudam a manter uma experiência coletiva distinta com relação ao saber e a seus limites.

A função do AE é de contribuir um pouquinho para essa aposta da escola, somente por um tempo. Ela não é, absolutamente, a de ser um exemplo de uma análise-modelo, pois, como dizia Freud (1926 [1925]/1976, p. 117), "manuais para a vida (Lebensführer) envelhecem rápido". Tudo isso é, sem dúvida, precário, mas era justamente com essa precariedade que Lacan esperava que se sustentasse o analista de sua escola (1970/2003, p. 276).

\section{Referências bibliográficas}

Freud, S. (1926 [1925]/1976). Inibição, sintoma e angústia. (Jayme Salomão, Trad.). In S. Freud. Edição standard brasileira das obras psicológicas completas de Sigmund Freud (Vol. 20, pp. 95-201). Rio de Janeiro: Imago.

Lacan, J. (1966/1998). De nossos antecedentes. In J. Lacan. Escritos (pp. 69-76). (Vera Ribeiro, Trad.). Rio de Janeiro: Jorge Zahar.

Lacan, J. (1967/1968). Discours de clôture des Journées sur la psychose. In M. Mannoni (Org.) Recherches, 8, Enfance aliénée II. L’enfant, la psychose et l'institution. Paris: CERFI.

Lacan, J. (1967/2003). Proposição de 9 de outubro de 1967 sobre o psicanalista da escola. In J. Lacan. Outros escritos (pp. 248-264). (Vera Ribeiro, Trad.). Rio de 
Janeiro: Jorge Zahar.

Lacan, J. (1969/2003). O ato psicanalítico. Resumo do seminário de 1967-1968. In

J. Lacan. Outros escritos (pp. 371-379). (Vera Ribeiro, Trad.). Rio de Janeiro: Jorge Zahar.

Lacan, J. (1970/2003). Discurso na Escola Freudiana de Paris. In J. Lacan. Outros escritos (pp. 265-287). (Vera Ribeiro, Trad.). Rio de Janeiro: Jorge Zahar.

Lacan, J. (1970-1971/2009). O seminário, livro 18: de um discurso que não fosse semblante. (Vera Ribeiro, Trad.). Rio de Janeiro: Jorge Zahar.

Lacan, J. O aturdito (1972/2003). In J. Lacan. Outros escritos (pp. 448-497). (Vera Ribeiro, Trad.). Rio de Janeiro: Jorge Zahar.

Lacan, J. (1972-1973/2008). O seminário, livro 20: mais, ainda. (M. D. Magno, Trad.). Rio de Janeiro: Jorge Zahar.

Lacan, J. (1973/2003a). Nota italiana. In J. Lacan. Outros escritos (pp. 311-315). (Vera Ribeiro, Trad.). Rio de Janeiro: Jorge Zahar.

Lacan, J. (1973/2003b). Introdução à edição alemã de um primeiro volume dos Escritos. In J. Lacan. Outros escritos (pp. 550-556). (Vera Ribeiro, Trad.). Rio de Janeiro: Jorge Zahar.

Lacan, J. (1973-1974). O seminário, livro 21: os não-tolos erram. Inédito.

Lacan, J. (1974/2003). Televisão. In J. Lacan. Outros escritos (pp. 508-543). (Vera Ribeiro, Trad.). Rio de Janeiro: Jorge Zahar.

Lacan, J. (1976/2003). Prefácio à edição inglesa do Seminário 11. In J. Lacan. Outros escritos (pp. 567-569). (Vera Ribeiro, Trad.). Rio de Janeiro: Jorge Zahar.

Recebido: 20/11/2017

Aprovado: 15/01/2018 